\title{
Enhancing the Immune Response of a Nicotine Vaccine with Synthetic Small “Non-Natural” Peptides
}

\author{
Hoang-Thanh Le ${ }^{1,2,3,4, *}$, Nya L. Fraleigh ${ }^{1}$, Jordan D. Lewicky ${ }^{1}$, Justin Boudreau ${ }^{1}$, \\ Paul Dolinar ${ }^{1,2}$, Nitin Bhardwaj ${ }^{5}$, Francisco Diaz-Mitoma ${ }^{4,6}$, Sabine Montaut ${ }^{3}$ (D), \\ Sarah Fallahi ${ }^{1}$ and Alexandrine L. Martel ${ }^{1}$ \\ 1 Health Sciences North Research Institute, 56 Walford Road, Sudbury, ON P3E 2H3, Canada; \\ nfraleigh@hsnri.ca (N.L.F.); jlewicky@hsnri.ca (J.D.L.); jboudreau@hsnri.ca (J.B.); \\ dolinar.paul@gmail.com (P.D.); Sara.Fallahi@turnstonebio.com (S.F.); amartel@hsnri.ca (A.L.M.) \\ 2 Department of Biology, Laurentian University, 935 Ramsey Lake Road, Sudbury, ON P3E 2C6, Canada \\ 3 Department of Chemistry and Biochemistry, Biomolecular Sciences Programme, Laurentian University, \\ 935 Ramsey Lake Road, Sudbury, ON P3E 2C6, Canada; smontaut@laurentian.ca \\ 4 Northern Ontario School of Medicine, 935 Ramsey Lake Road, Sudbury, ON P3E 2C6, Canada; \\ mitoma99@gmail.com \\ 5 Division of Comparative Medicine, University of Toronto, 1 King's College Circle, \\ Toronto, ON M5S 1A8, Canada; nitin.bhardwaj@utoronto.ca \\ 6 VBI Vaccines Inc., 310 Hunt Club Road East, Suite 201, Ottaway, ON K1V 1C1, Canada \\ * Correspondence: hle@hsnri.ca; Tel.: +1-705-523-7300 (ext. 2613)
}

Academic Editors: Paula A. C. Gomes, Stefania Galdiero and Cátia Teixeira Received: 13 February 2020; Accepted: 7 March 2020; Published: 12 March 2020

\begin{abstract}
The addictive nature of nicotine is likely the most significant reason for the continued prevalence of tobacco smoking despite the widespread reports of its negative health effects. Nicotine vaccines are an alternative to the currently available smoking cessation treatments, which have limited efficacy. However, the nicotine hapten is non-immunogenic, and successful vaccine formulations to treat nicotine addiction require both effective adjuvants and delivery systems. The immunomodulatory properties of short, non-natural peptide sequences not found in human systems and their ability to improve vaccine efficacy continue to be reported. The aim of this study was to determine if small "non-natural peptides," as part of a conjugate nicotine vaccine, could improve immune responses. Four peptides were synthesized via solid phase methodology, purified, and characterized. Ex vivo plasma stability studies using RP-HPLC confirmed that the peptides were not subject to proteolytic degradation. The peptides were formulated into conjugate nicotine vaccine candidates along with a bacterial derived adjuvant vaccine delivery system and chitosan as a stabilizing compound. Formulations were tested in vitro in a dendritic cell line to determine the combination that would elicit the greatest $1 \mathrm{~L}-1 \beta$ response using ELISAs. Three of the peptides were able to enhance the cytokine response above that induced by the adjuvant delivery system alone. In vivo vaccination studies in $\mathrm{BALB} / \mathrm{c}$ mice demonstrated that the best immune response, as measured by nicotine-specific antibody levels, was elicited from the conjugate vaccine structure, which included the peptide, as well as the other components. Isotype analyses highlighted that the peptide was able to shift immune response toward being more humorally dominant. Overall, the results have implications for the use of non-natural peptides as adjuvants not only for the development of a nicotine vaccine but also for use with other addictive substances and conventional vaccination targets as well.
\end{abstract}

Keywords: peptide solid phase synthesis; non-natural peptides; vaccine delivery; IL-1 $\beta$; bacterial derived adjuvant; phagocytic cells; dendritic cells; macrophages; immune responses 


\section{Introduction}

Peptides have been used in various applications in medicine, immunology, and pharmacology for the creation of substances including macrocyclic antibiotics, integrin inhibitors, anticancer agents, neuromodulators, opioids, and hormones [1-6]. A new direction in peptide research involves the use of synthetic peptides in immunotherapies and vaccines where they can act as both antigens and as components of adjuvants and delivery systems [7-10]. A number of peptide vaccines are in various stages of development, offering hope for the control of numerous diseases caused by HIV, Influenza A, and Hepatitis C [11-13].

The frequency of different lengths of peptide sequences in the universal proteome database has been investigated using bioinformatics tools. Interestingly, while all possible four amino acid (aa) sequences occur at least once in humans and all other organisms, there are certainly 5 aa or 6 aa combinations that are absent $[14,15]$. Short peptide sequences of $5-6$ aa have been shown to be important in a variety of biological processes, including immune activation, and combining vaccine candidates with immunomodulatory peptides has been an effective strategy to enhance immunogenicity [16-19]. Kobinger's group screened the UniRef100 universal proteome database and identified a large pool of rare or "non-natural" 5 aa pentapeptides that were screened for immunomodulatory activity [20,21]. Many of the pentapeptides were able to strengthen immune responses when added to a vaccine complex, without increasing the possibility of adverse inflammatory reactions. The pentapeptide (Peptide 1, Table 1) demonstrated superior activity in combination with both influenza and hepatitis $B$ vaccines [22]. Overall, there are several advantages for rare short peptides as immunostimulants. They can improve both humoral and cellular immune responses to vaccine antigens while remaining non-immunogenic themselves. In addition, they can also work synergistically with other adjuvants in improving immune responses while being both non-toxic and easy/inexpensive to prepare [21].

Table 1. Synthetic peptides and amino acid sequences.

\begin{tabular}{cc}
\hline Peptide & Amino Acid Sequence \\
\hline $\mathbf{1}$ & KWCEC \\
$\mathbf{2}$ & KWCECKFFKFFG \\
$\mathbf{3}$ & KWCECEFFEFFG \\
$\mathbf{4}$ & Succinamic-KWCEC \\
\hline
\end{tabular}

The conjugation of a non-natural pentapeptide with a hapten antigen such as nicotine may provide the necessary signals to enable the recognition and stimulation of an immune response. Tobacco smoking is a global pandemic causing 8 million deaths per year [23] and yet smoking cessation remains relatively unsuccessful due to nicotine addiction. The development of a therapeutic nicotine vaccine offers one of the most promising treatment options to date, where the induction of a potent and selective antibody response against nicotine would block its addictive effects in the central nervous system. As nicotine is non-immunogenic, immunogenicity needs to be increased through conjugation to a peptide or protein carrier, and the use of adjuvants [24]. A successful vaccination strategy is, therefore, dependent upon the appropriate hapten design, carrier protein, and adjuvant, all of which affect both the magnitude and affinity of the immune response elicited [25-27]. We have been developing a mucosal nicotine vaccine that employs a naturally adjuvanted delivery system derived from the outer membrane of bacteria (Neisseria meningitidis or Vibrio cholerae) [28-30], and a synthetic non-natural peptide that facilitates nicotine conjugation. The preparation of the adjuvant system, which we have coined bacterial derived adjuvant (BDA), was previously described by our group [28,29]. Importantly, our nicotine vaccine is unlike previous vaccines [31-35] and has been designed to be administered via an intranasal (IN) route. The BDA vaccine delivery system generates a robust immune response by stimulating IL-1 $\beta$ production through Toll-like receptor 4 (TLR4), a potent mechanism for mucosal immunity [28], resulting in high mucosal and systemic antibody levels in mice [28,29]. In this report, we further studied the potential use of the non-natural pentapeptides for enhancing the immune 
response of our nicotine vaccine. We report the synthesis and evaluation of several non-natural peptides (Table 1) as potential immunostimulants. Nicotine vaccines were formulated in the presence of the peptides and the BDA at a 1:5 ratio of BDA:Peptide ( $w / w$, based on BDA protein). At this ratio, the degree of nicotine conjugation was up to five times higher than without the peptides (as visualized by TLC with detection by Dragendorff reagent). The formulations were first screened in vitro for their ability to induce IL-1 $\beta$ production. The best formulation was carried forward for in vivo studies in mice, where the contribution of each of the components of the vaccine to the immune response was assessed by measuring the levels of both nicotine-specific IgG and different IgG isotypes. Overall, the results clearly indicate that the non-natural peptides are capable of enhancing the immune response toward our nicotine vaccine.

\section{Results and Discussion}

The peptides that were prepared included the pentapeptide previously reported by Kobinger's group [20-22], as well as several extended analogs that contain this 5 aa sequence (Table 1). Peptides 2 and $\mathbf{3}$ are dodecapeptides that have additional lysine and glutamic acid residues, respectively, to increase branching points, as well as phenylalanine residues to promote pi-pi intermolecular interactions, all of which provide additional sites for nicotine conjugation and could aid in nanoparticle self-assembly [36]. Peptide 4 contains a succinamic acid residue at the N-terminal for the potential binding to nicotine. All of the peptides were synthesized using our standard solid-phase synthesis protocol with some modifications [5] and were obtained in moderate-to-good yield with high purity (Table 2). The plasma stability of pentapeptide 1 was assessed using RP-HPLC and our previously published methods [37], with results confirming that the peptide sequence was not recognized and cleaved by proteolytic enzymes (Figure 1), and would likely improve the overall stability of the conjugate vaccine in vivo.

Table 2. Synthetic peptide identification and characterization.

\begin{tabular}{|c|c|c|c|c|c|}
\hline Peptide & Ninhydrin Test & Scale and Yield & $H P L C t_{R}(\min )$ & \multicolumn{2}{|c|}{ Mass Spectrometry } \\
\hline 1 & Positive & $\begin{array}{c}300 \mathrm{nmol} \\
100 \mathrm{mg}(50.0 \%)\end{array}$ & 14.8 & $\begin{array}{l}\text { Calculated: } \\
\text { Measured: }\end{array}$ & $\begin{array}{c}667.25 \\
668.1(\mathrm{M}+\mathrm{H})^{+}\end{array}$ \\
\hline 2 & Positive & $\begin{array}{c}200 \mathrm{nmol} \\
240 \mathrm{mg}(76.5 \%) \\
\end{array}$ & 20.8 & $\begin{array}{l}\text { Calculated: } \\
\text { Measured: }\end{array}$ & $\begin{array}{c}1568.73 \\
785.5(\mathrm{M}+2 \mathrm{H})^{2+}\end{array}$ \\
\hline 3 & Positive & $\begin{array}{c}200 \mathrm{nmol} \\
45 \mathrm{mg}(14.3 \%)\end{array}$ & 23.7 & $\begin{array}{l}\text { Calculated: } \\
\text { Measured: }\end{array}$ & $\begin{array}{c}1571.8 \\
786.4(\mathrm{M}+2 \mathrm{H})^{2+}\end{array}$ \\
\hline 4 & Positive & $\begin{array}{c}100 \mathrm{nmol} \\
37 \mathrm{mg}(48.2 \%)\end{array}$ & 16.5 & $\begin{array}{l}\text { Calculated: } \\
\text { Measured: }\end{array}$ & $\begin{array}{c}766.87 \\
767.3(\mathrm{M}+\mathrm{H})^{+}\end{array}$ \\
\hline
\end{tabular}

Dendritic cells are a crucial link between the innate and acquired immunity as they are adept in phagocytosis, secretion of cytokines, and antigen presentation. Activated antigen-presenting cells are required to initiate T-cell-mediated immune responses to a foreign substance [38]. By using IL-1 $\beta$ secretion to detect the activation of these professional antigen-presenting cells, the initial response was quickly assessed. Treatment with the synthetic peptides alone does not induce IL- $1 \beta$ release when evaluated by ELISA (data not shown). This was not surprising, as functional IL- $1 \beta$ secretion is dependent upon two signals, resulting in the activation of the inflammasome and caspase 1 to cleave the pro-IL-1 $\beta$ [39]. When combined with the BDA, in respective nicotine vaccine formulations, IL- $1 \beta$ production was maintained with all of the peptides (Figure 2). Interestingly, formulation with peptides 3 or 4 and their extended amino acid sequences, both enhanced the cytokine response to approximately the same extent, while there was no statistical difference with the formulation containing the extended peptide 2 as compared to the BDA alone. Cytokine levels with the formulation containing the core pentapeptide 1 were enhanced to the greatest degree. This stronger proinflammatory cytokine release would theoretically drive a stronger adaptive immune response against nicotine, resulting in a more effective vaccine. Overall, each of the peptides can be used with BDA to improve the degree of nicotine 
conjugation, while some offer the additional benefit of increased immunostimulatory activity. In this study, the formulation containing peptide 1 was selected to be used for in vivo evaluations.

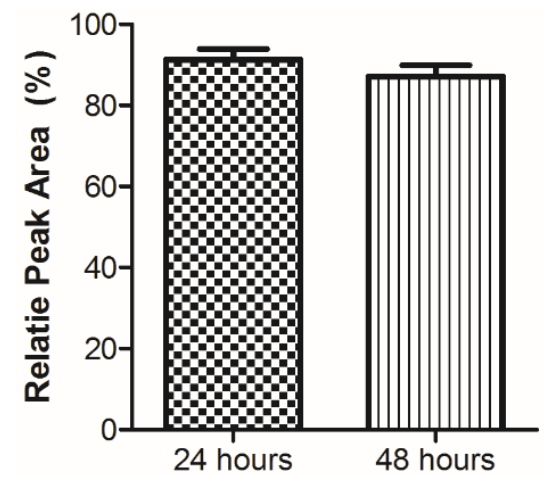

Figure 1. Peptide stability in plasma. Pentapeptide 1 was incubated in human plasma at $37^{\circ} \mathrm{C}$. Levels of the peptide remaining after various time points were analyzed by RP-HPLC in the presence of $0.1 \%$ trifluoroacetic acid and detected by absorbance at $210 \mathrm{~nm}$. Peptide amounts were calculated relative to quantities determined at time point zero, and data shown are the average \pm SEM of three separate experiments. No statistical difference was found between the two time points.

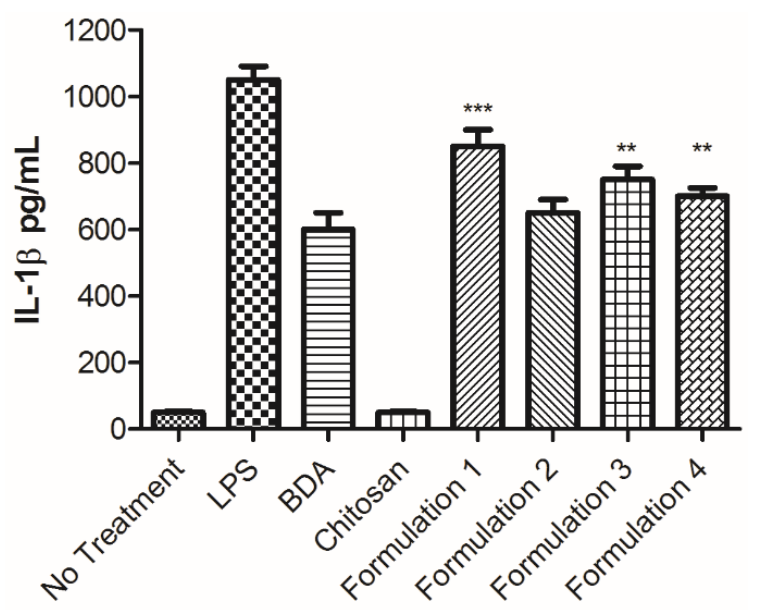

Figure 2. Levels of IL-1 $\beta$ produced by JAWSII after $48 \mathrm{~h}$. JAWSII, immortalized bone-marrow-derived dendritic cells, were seeded at a concentration of $10^{6}$ cells $/ \mathrm{mL} /$ well in a 12-well plate and left untreated or treated with either $1 \mu \mathrm{g} / \mathrm{mL}$ LPS from E. coli 0111:B4, vaccine components (bacterial derived adjuvant (BDA): $1 \mu \mathrm{g} / \mathrm{mL}$, chitosan: $10 \mu \mathrm{g} / \mathrm{mL})$, or the different peptides (1-4) containing formulations $(1 \mu \mathrm{g} / \mathrm{mL}$ based on BDA). Supernatants were collected from the cells after $48 \mathrm{~h}$ of treatment and levels of IL-1 $\beta$ were analyzed via ELISA. $N=6 \pm$ SEM. Statistical significance was determined by an ANOVA with a Tukey HSD. ${ }^{* * *} p<0.001$ and ${ }^{* *} p<0.01$ as compared to BDA.

We evaluated the contribution of each of the components of the IN delivered nicotine vaccine to the immune responses in vivo using BALB/c mice (Figure 3), including pentapeptide 1 (Table 1). The formulation containing only the BDA induced the lowest levels of nicotine-specific IgG. Overall, the strongest immune responses were observed in the formulations containing the synthetic pentapeptide 1, and responses were significantly improved as compared to Groups 2 and 3, which lack the pentapeptide. Peptide $\mathbf{1}$ also appears to reduce the variability between the individual mice vaccinated IN, as seen in Figure 3A, and including chitosan as a stabilizing component served to increase the immune responses, which was most evident after the third blood collection. This is in line with our previous publication, which demonstrated that the IN conjugate-nicotine vaccine was able to prevent nicotine from entering the brain after vaccination using $\left[{ }^{3} \mathrm{H}\right]$-nicotine challenges in vivo, leading to a fourfold reduction in brain nicotine concentrations, as compared to controls [28]. 
A)

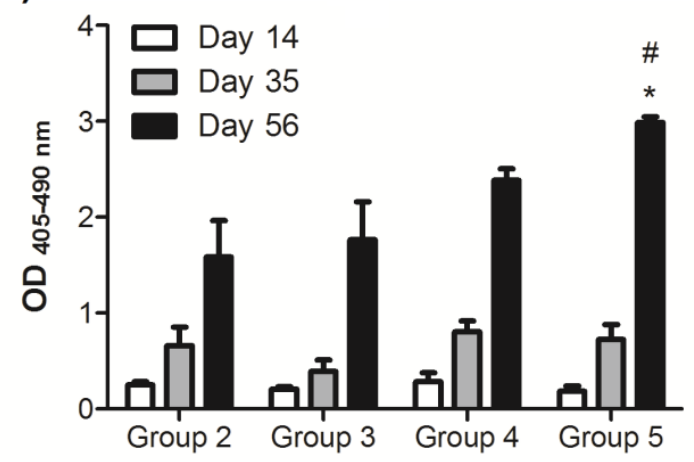

B)

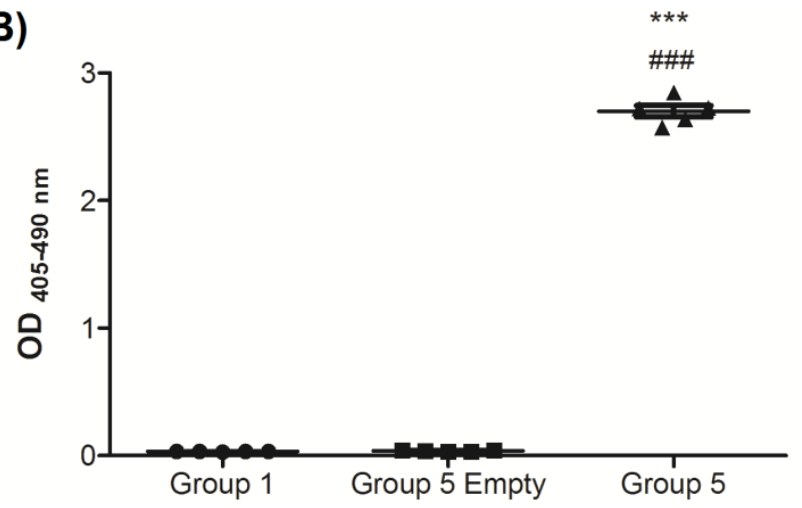

Figure 3. Levels of anti-nicotine IgG. Female BALB/c mice were administered intranasal installations of either PBS (Group 1) or different nicotine vaccine formulations: [BDA/Nic Hapten] (Group 2), [BDA/Nic Hapten /Chitosan] (Group 3), [BDA/Peptide 1/Nic Hapten] (Group 4), and [BDA/Peptide 1/Nic Hapten/Chitosan] (Group 5); Group 5 Empty refers to the delivery system without nicotine. Blood was collected two weeks post-vaccination (Day 14, 35, 56, and 77). (A) Anti-nicotine IgG from individual sera and diluted 1:300. Data are represented as \pm SEM ( $n=4-5$ for each group). Statistical significance was determined by a Kruskal-Wallis with a Dunn's multiple comparison test * $p<0.05$ as compared to Group 2 and \# $p<0.05$ as compared to Group 3. (B) In a repeated trial, the total anti-nicotine IgG present was detected in sera (1:600 dilution). Each point represents an individual mouse and data are represented as \pm SEM, $n=5$. Statistical significance was determined by an ANOVA with a Tukey HSD. *** $p \leq 0.001$ as compared to Group 1 and \#\#\# $p \leq 0.001$ as compared to Group 5 Empty.

The full vaccine formulation containing the pentapeptide, chitosan, and BDA provided the best results, with antibody levels that, upon repeated trials, were consistently saturated by the fourth bleed, even at dilution of 1:600 (Figure 3B). In subsequent investigations, we were able to determine that dilutions on the order of greater than $10^{4}$ were needed in order to stop saturation (data not shown). In order to conclude that the delivery system was not inducing non-specific reactions during the ELISA protocol, an additional negative control was added in the repeated trial (Group 5 Empty). Peptide 1 also appears to shift the anti-nicotine IgG isotype response toward a more IgG1-dominant phenotype, suggesting a stronger polarization toward a Th2 response, as seen in Figure 4. The BDA/Nic Hapten formulation had a balanced IgG1:IgG2a ratio, and when Peptide $\mathbf{1}$ was added in Groups 4 and 5, there is a significant shift toward an IgG1-dominated response, which is strongest in the full formulation (Group 5).

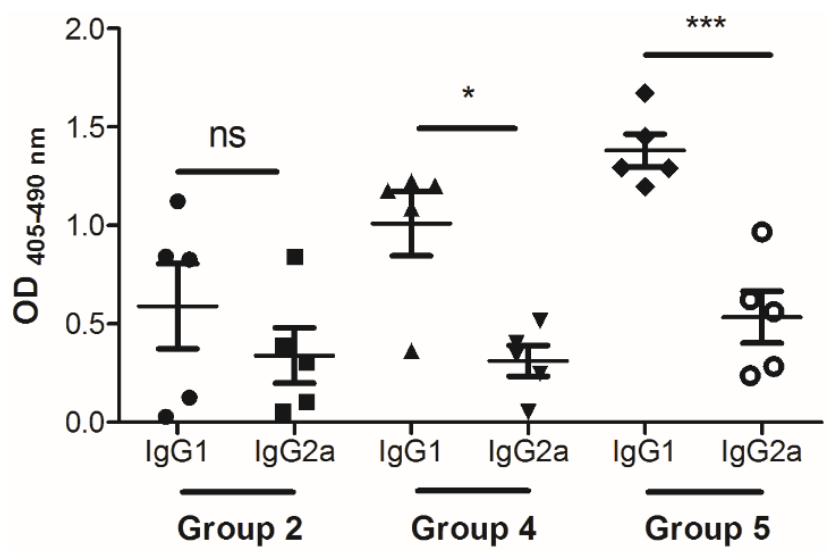

Figure 4. Levels of anti-nicotine IgG isotypes. Female BALB/c mice were administered intranasal instillations of different nicotine vaccine formulations and blood was collected two weeks post-vaccination. Individual mouse sera were diluted and anti-nicotine IgG1 and IgG2a were assessed on day 77. Data are represented as $\pm \mathrm{SEM}, \mathrm{n}=5$. Statistical significance was determined for Group 5 by an unpaired 2-tailed T-test, ${ }^{* * *} p=0.0006$, and for Group 4 by a Mann-Whitney test, ${ }^{*} p=0.0317$. 
It appears that the in vitro assessment of IL- $1 \beta$ is a useful tool to screen these adjuvant formulations for potential in vivo performance as it can enhance antigen presentation and humoral immune responses [40-44]. This is reflected in the data as the BDA group alone was not as effective as an adjuvant of the nicotine vaccine as compared to Formulation 1 and vaccine Group 5 for in vitro and in vivo testing, respectively.

\section{Materials and Methods}

\subsection{Peptide Synthesis}

Peptides were synthesized by solid phase synthesis on a Symphony 12-Channel Multiplex Synthesizer (Protein technologies Inc., Tucson, AZ, USA), using a combination of manual and automated synthesis, following the conventional Fmoc/HBTU methodology. As an example for peptide 1, the Fmoc-Cys(Trt)-NovaSynTGT Resin (ca. $500 \mathrm{mg} ; 0.2 \mathrm{meq} / \mathrm{g} ; 1 \mathrm{mmol}$ ) was swollen in dimethylformamide $(\mathrm{DMF})$ and then thoroughly washed using DMF $(2 \times 5 \mathrm{~mL})$. The remaining amino acids were coupled on the resin by repeated cycles of Fmoc-deprotection, activation, and coupling. Each deprotection step involved a double treatment with $20 \%$ piperidine in DMF (20 min total) followed by washing with DMF $(6 \times 5 \mathrm{~mL})$ and ninhydrin testing. Each activation step was performed by mixing the protected amino acid ( $0.8 \mathrm{mmol}$ in $2.7 \mathrm{~mL}$ DMF) with HBTU $(0.7 \mathrm{mmol}$ in DMF) and a slight excess of $N, N$-diisopropylethylamine $(1.6 \mathrm{mmol})$ for $5 \mathrm{~min}$. The activated amino acid was then allowed to couple to the resin for $1.5 \mathrm{~h}$ with nitrogen bubbling. The peptide-resin was thoroughly washed with DMF $(6 \times 5 \mathrm{~mL})$ after coupling and a ninhydrin test was performed to ensure completion. Upon completion of synthesis, the N-terminal Fmoc group was removed under standard conditions, and the peptide-resin was washed with DMF.

Peptides were cleaved using a trifluoroacetic acid (TFA) cocktail (TFA: Thioanisole: Phenol: $\mathrm{H}_{2} \mathrm{O}$ : 1,2-ethanedithiol: Triisopropylsilane (81.5:5:5:2.5:1)) for $3 \mathrm{~h}$. The products were then collected and washed with $2 \times 5 \mathrm{~mL}$ TFA. The filtrate was evaporated in vacuo and then precipitated by using cold ether $(30 \mathrm{~mL})$. After decanting the ether layer, the peptide was washed with cold ether $(2 \times 10 \mathrm{~mL})$, dried in a desiccator overnight, dissolved in double-distilled $\mathrm{H}_{2} \mathrm{O}$, and lyophilized to yield the crude peptide.

Crude peptides were purified by HPLC on a Dionex UltiMate 3000 UHPLC system (Thermo Scientific, Mississauga, ON, Canada) fitted with a PrepPak Cartridge (C-18, 15-20 $\mu \mathrm{m}$, $25 \mathrm{~mm} \times 100 \mathrm{~mm}$, Waters, Mississauge, ON, Canada) on a PrepLC 25 Module (Waters, Mississauga, ON, Canada) using a binary gradient of aqueous $0.1 \%$ TFA (solvent A) and $80 \%$ acetonitrile containing $0.1 \%$ TFA (solvent B) at a flow rate of $10.0 \mathrm{~mL} / \mathrm{min}$. The gradient consisted of $10 \mathrm{~min}$ of solvent A running through the column. The gradient then began to transition from solvent A to solvent B over $30 \mathrm{~min}$. Solvent B was then run through the column for an additional $20 \mathrm{~min}$. The eluent was monitored at 210 and $260 \mathrm{~nm}$ and collected into fractions. UV absorbing fractions were collected and then characterized by analytical HPLC and electrospray ionization mass spectrometry (ESI-MS, Shimadzu Corporation, Kyoto, Japan). Analytical HPLC was carried out on

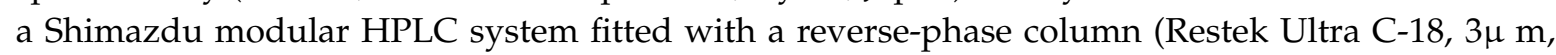
$4.6 \mathrm{~mm} \times 150 \mathrm{~mm})$ and running solvent A $(0.1 \%$ aqueous TFA) and solvent B $(0.1 \%$ TFA in $95 \%$ acetonitrile) at $0.7 \mathrm{~mL} / \mathrm{min}$. The first $10 \mathrm{~min}$ consisted solely of solvent A running through the column. The gradient then began to transition from solvent A to solvent B over 20 min. Solvent B was then run through the column for an additional $10 \mathrm{~min}$. The purified peptide was lyophilized and analyzed by ESI-MS on an 6120 Quadropole LC/MS (Agilent Technologies, Inc., Toronto, ON, Canada) operating in positive mode with a scanning range from 105 to $1300 \mathrm{~m} / z$, a $\mathrm{N}_{2}$ gas temperature of $350{ }^{\circ} \mathrm{C}$, and a voltage at $4 \mathrm{kV}$. Fractions of sufficient purity were combined and lyophilized to yield the desired peptides at a high level of purity. The detailed characterization and identification of peptides are summarized in Supplementary Materials document. 


\subsection{Plasma Stability Analysis}

Blood was collected from healthy volunteers in EDTA blood collection tubes (BD Vacutainer, Mississauga, ON, Canada). Plasma was collected after centrifugation at $900 \times g$ and $20^{\circ} \mathrm{C}$ for $10 \mathrm{~min}$ with decreased deceleration, aliquoted, and stored at $-80^{\circ} \mathrm{C}$. All subjects gave their informed consent for inclusion before they participated in the study. The study was conducted in accordance with the Declaration of Helsinki, with all protocols approved by the Research Ethics Board at Health Sciences North Research Institute (Protocol \# 18-061).

The stability of pentapeptide $\mathbf{1}$ in human plasma was analyzed using previously published methods [37].

\subsection{Formulation and Vaccine Preparation}

Formulations (1-4) were prepared by conjugation of the corresponding peptide (1-4,Table 1$)$ with the BDA [28-30] (2-5 mg/mL in water based on protein content determined using Thermo Scientific Pierce BCA Protein Assay Kit) at pH 5-6 in the presence of EDC coupling reagent (Sigma Aldrich, Saint Louis, MO, USA, 10 equiv. based on BDA protein content).

Vaccines (Table 3) were prepared as previously described [29] by conjugation of 3'-aminomethylnicotine (Toronto Research Chemicals Inc., Toronto, ON, Canada, $25 \mathrm{mg} / \mathrm{mL}$ in $\mathrm{MeOH})$ with the BDA component $(2-5 \mathrm{mg} / \mathrm{mL}$ in water based on protein), with or without peptide 1 and the addition of chitosan as a stabilizing compound at pH5-6 in the presence of EDC coupling reagent (10 equiv. based on nicotine hapten concentration). Nicotine was quantified during the conjugation reaction using the UV absorption of derived nicotine as a standard at $265 \mathrm{~nm}$ and detected by TLC on Silica gel 60 F254 (EM Science, Gibbstown, NJ, USA) with Dragendorff reagent staining.

All final conjugation products were purified by dialysis in HEPES buffer with $0.01 \%$ Tween 80 , and vaccines were lyophilized using different freeze-drying techniques. Particle size as a parameter for stability analysis was analyzed by dynamic light scattering with a Zetasizer NanoZS (Malvern Instruments, Malvern, United Kingdom) equipped with a $4 \mathrm{~mW} 633 \mathrm{~nm}$ He-Ne laser, an avalanche photodiode positioned $175^{\circ}$ to the beam, and a temperature-controlled cuvette holder. Instrument parameters were determined automatically along with measurement times. The conjugate vaccine systems (2-5 mg/mL based on nicotine concentration) were stored at either $4{ }^{\circ} \mathrm{C}$ (solution form) or at room temperature (solid form) before being used for in vivo animal studies or in vitro testing.

Table 3. Vaccine group composition.

\begin{tabular}{cc}
\hline Vaccine & Composition \\
\hline 2 & BDA + Nicotine \\
3 & BDA + Nicotine/Chitosan \\
4 & BDA + Nicotine + Peptide 1 \\
5 & BDA + Nicotine + Peptide 1/Chitosan \\
\hline
\end{tabular}

\subsection{In Vitro Studies}

To investigate the peptides' effect on nicotine vaccine formulations in vitro, JAWSII cells (bone marrow-derived dendritic cell line from p53 -/- C57BL/6 mice) were grown to confluency in RPMI 1640 supplemented with 8\% FBS (Gibco, Life Technologies, Mississauga, ON, Canada), $1 \%$ penicillin/streptomycin, and $5 \mathrm{ng} / \mathrm{mL}$ GM-CSF (Gibco, Life Technologies, Mississauga, ON, Canada) in the presence of $5 \% \mathrm{CO}_{2}$ at $37^{\circ} \mathrm{C}$. Cells were seeded at a concentration of $10^{6}$ cells $/ \mathrm{mL}$ and treated with either $1 \mu \mathrm{g} / \mathrm{mL}$ LPS from E. coli 0111:B4 (Sigma, St. Louis, MO, USA), vaccine components BDA $(1 \mu \mathrm{g} / \mathrm{mL})$ or chitosan $(10 \mu \mathrm{g} / \mathrm{mL})$, or formulations $1-4(1 \mu \mathrm{g} / \mathrm{mL}$ based on BDA) for $48 \mathrm{~h}$. Supernatants were analyzed for levels of IL-1 $\beta$ using a commercial ELISA (eBioscience, San Diego, CA, USA). The assay was performed as per the instructions from the manufacturer, and the limit of detection was $7.8 \mathrm{pg} / \mathrm{mL}$. 


\subsection{In Vivo Vaccination}

Six- to eight-week-old female BALB/c mice were purchased from Charles River (Montreal, QC, Canada). Mice were housed at the Laurentian University Animal Care Facility and were supplied food and water ad libitum. All protocols were approved by the Animal Care Committee at Laurentian University (Protocol \#2013-04-02). The animal room was maintained at a temperature of $21 \pm 2{ }^{\circ} \mathrm{C}$ and a relative humidity of $55 \% \pm 5 \%$. These parameters were recorded daily in addition to maintaining $12 \mathrm{~h}$ light and dark cycles. Mice were allowed to acclimatize to their surroundings for one week prior to the commencement of the experimental protocol and were randomly placed into groups of 5 . Animals were anesthetized using either a ketamine/xylazine (Wyeth, Guelph, ON, Canada/ LLOYD Inc., Shenandoah, IA, USA) cocktail or isoflurane.

All 5 groups of animals were immunized IN with the prime vaccination on day 0 , and booster vaccinations on days 21,42, and 63 with a fixed amount of vaccine corresponding to $10 \mu \mathrm{g}$ of nicotine ( $20 \mu \mathrm{L}$ total volume, $10 \mu \mathrm{L}$ per nare). Group 1 received PBS, while Groups $2-5$ received vaccines $2-5$, respectively. Sera were harvested from blood samples collected via retro-orbital bleed or the submandibular vein on days $14,35,56$, and 77 . Nicotine-specific antibodies in sera were assayed following a previously reported ELISA protocol [28,29].

\section{Conclusions}

The immunomodulatory mechanisms of certain non-natural short peptide sequences continue to be reported. We have shown here that the immunostimulatory activity of a pentapeptide member of this family is capable of enhancing antigen-specific immune responses toward our nicotine vaccine candidate. Overall, the peptide was able to increase nicotine conjugation with the BDA, with the stability of the conjugate system likely also improved. Importantly, the peptide improved immune response homogeneity, and shifted antibody isotypes toward a predominantly IgG1 response. The results have implications for the use of non-natural peptides as adjuvants in the development of new vaccines against not only conventional targets such as bacteria and viruses, but against other addictive substances as well.

Supplementary Materials: The following are available online. Figure S1: KWCEC peptide HPLC results $(99.38 \%$ purity), Figure S2: KWCEC peptide ESI-MS results, Figure S3: KWCECKFFKFFG peptide HPLC results (97.32\% purity), Figure S4: KWCECKFFKFFG peptide ESI-MS results. Figure S5: KWCECEFFEFFG peptide HPLC results (89.37\% purity), Figure S6: KWCECEFFEFFG peptide ESI-MS results, Figure S7: Succinamic KWCEC peptide HPLC results (98.76\% purity), Figure S8: Succinamic KWCEC peptide ESI-MS results.

Author Contributions: Conceptualization, H.-T.L., N.L.F. and J.D.L.; methodology, H.-T.L., N.L.F., J.D.L., N.B., F.D.-M. and S.F.; validation, H.-T.L., N.L.F., J.D.L, N.B., F.D.-M. and S.M.; investigation, H.-T.L., N.L.F., J.D.L., J.B., P.D., N.B., S.M. and S.F.; writing-original draft preparation, H.-T.L., N.L.F., J.D.L., J.B., S.M. and A.L.M.; writing-review and editing, H.-T.L., N.L.F., J.D.L., J.B., S.M. and A.L.M.; visualization, H.-T.L., N.L.F., J.D.L., J.B., S.M. and A.L.M.; supervision, H.-T.L.; project administration, H.-T.L. and F.D.-M.; funding acquisition, H.-T.L. All authors have read and agreed to the published version of the manuscript.

Funding: This study was conducted with the support of the Grand Challenges of Canada (GCC \# S4-0212-01), the Northern Cancer Foundation, and the Canadian Institute of Health Research Project Grant PJT-148531 (to H.T.L.). The financial support from the Natural Sciences and Engineering Research Council of Canada (Research Tools and Instruments Program), Laurentian University, Canadian Foundation for Innovation (Leaders Opportunity Fund)-Ontario Research Fund is gratefully acknowledged by S.M.

Acknowledgments: The authors wish to thank Rebecca Letto for her technical assistance. The authors also wish to thank Gerardo Ulibarri (Laurentian University) for the use of his HPLC equipment and access to his laboratory.

Conflicts of Interest: The authors declare no conflict of interest. The funders had no role in the design of the study; in the collection, analyses, or interpretation of data; in the writing of the manuscript, or in the decision to publish the results. 


\section{References}

1. Fosgerau, K.; Hoffmann, T. Peptide therapeutics: Current status and future directions. Drug Discov. Today 2015, 20, 122-128. [CrossRef]

2. Lau, J.L.; Dunn, M.K. Therapeutic peptides: Historical perspectives, current development trends, and future directions. Bioorg. Med. Chem. 2018, 26, 2700-2707. [CrossRef] [PubMed]

3. White, A.M.; Craik, D.J. Discovery and optimization of peptide macrocycles. Expert Opin. Drug Discov. 2016, 11, 1151-1163. [CrossRef] [PubMed]

4. Calvo Tardón, M.; Allard, M.; Dutoit, V.; Dietrich, P.Y.; Walker, P.R. Peptides as cancer vaccines. Curr. Opin. Pharmacol. 2019, 47, 20-26. [CrossRef]

5. Le, H.T.; Lemaire, I.; Gilbert, A.K.; Jolicoeur, F.; Lemaire, S. Bioactive peptidic analogues and cyclostereoisomers of the minimal antinociceptive histogranin fragment-(7-10). J. Med. Chem. 2003, 46, 3094-3101. [CrossRef] [PubMed]

6. Le, H.T.; Lemaire, I.; Gilbert, A.K.; Jolicoeur, F.; Leduc, N.; Yang, L.; Lemaire, S. Histogranin-like antinociceptive and anti-inflammatory derivatives of o-phenylenediamine and benzimidazole. J Pharmacol. Exp. Ther. 2004, 309, 146-155. [CrossRef] [PubMed]

7. Kumai, T.; Lee, S.; Cho, H.I.; Sultan, H.; Kobayashi, H.; Harabuchi, Y.; Celis, E. Optimization of peptide vaccines to induce robust antitumor CD4 T-cell responses. Cancer Immunol. Res. 2017, 5, 72-83. [CrossRef] [PubMed]

8. Yang, J.; Zhang, Q.; Li, K.; Yin, H.; Zheng, J.N. Composite peptide-based vaccines for cancer immunotherapy (Review). Int. J. Mol. Med. 2015, 35, 17-23. [CrossRef]

9. Skwarczynski, M.; Toth, I. Recent advances in peptide-based subunit nanovaccines. Nanomedicine 2014, 17, 2657-2669. [CrossRef]

10. Bezu, L.; Kepp, O.; Cerrato, G.; Pol, J.; Fucikova, J.; Spisek, R.; Zitvogel, L.; Kroemer, G.; Galluzzi, L. Trial watch: Peptide-based vaccines in anticancer therapy. Oncoimmunology 2018, 7, e15111506. [CrossRef]

11. Combadière, B.; Beaujean, M.; Chaudesaigues, C.; Vieillard, V. Peptide-Based Vaccination for Antibody Responses Against HIV. Vaccines 2019, 7, 105. [CrossRef] [PubMed]

12. Herrera-Rodriguez, J.; Meijerhof, T.; Niesters, H.G.; Stjernholm, G.; Hovden, A.O.; Sørensen, B.; Ökvist, M.; Sommerfelt, M.A.; Huckriede, A. A novel peptide-based vaccine candidate with protective efficacy against influenza A in a mouse model. Virology 2018, 515, 21-28. [CrossRef]

13. Basirnejad, M.; Bolhassani, A. Development of HCV Therapeutic Vaccines Using Hp91 Peptide and Small Heat Shock Protein 20 as an Adjuvant. Protein Pept. Lett. 2018, 25, 924-932. [CrossRef] [PubMed]

14. Tuller, T.; Chor, B.; Nelson, N. Forbidden penta-peptides. Protein Sci. 2017, 16, 2251-2259. [CrossRef] [PubMed]

15. Otaki, J.M.; Gotoh, T.; Yamamoto, H. Potential implications of availability of short amino acid sequences in proteins: An old and new approach to protein decoding and design. Biotechnol. Annu. Rev. 2008, 14, $109-141$. [PubMed]

16. Lucchese, G.; Stufano, A.; Trost, B.; Kusalik, A.; Kanduc, D. Peptidology: Short amino acid modules in cell biology and immunology. Amino Acids 2007, 33, 703-707. [CrossRef]

17. Fu, X.; Tao, L.; Zhang, X. A short polypeptide from the herpes simplex virus type 2 ICP10 gene can induce antigen aggregation and autophagosomal degradation for enhanced immune presentation. Hum. Gene Ther. 2010, 21, 1687-1696. [CrossRef]

18. Saenz, R.; Souza Cda, S.; Huang, C.T.; Larsson, M.; Esener, S.; Messmer, D. HMGB1-derived peptide acts as adjuvant inducing immune responses to peptide and protein antigen. Vaccine 2010, 28, 7556-7562. [CrossRef]

19. Nicholls, E.F.; Madera, L.; Hancock, R.E. Immunomodulators as adjuvants for vaccines and antimicrobial therapy. Ann. N. Y. Acad. Sci. 2010, 1213, 46-61. [CrossRef]

20. Patel, A.; Dong, J.C.; Trost, B.; Richardson, J.S.; Tohme, S.; Babiuk, S.; Kusalik, A.; Kung, S.K.; Kobinger, G.P. Pentamers not found in the universal proteome can enhance antigen specific immune responses and adjuvant vaccines. PLoS ONE 2012, 7, e43802. [CrossRef]

21. Dong, J.C.; Kobinger, G.P. Hypothesis driven development of new adjuvants: Short peptides as immunomodulators. Hum Vaccin. Immunother. 2013, 9, 808-811. [CrossRef] [PubMed]

22. Patel, A.; Kobasa, D.; Kobinger, G.P.; Babiuk, S. Peptide Adjuvants. U.S. Patent 9,211,325, 15 December 2015.

23. World Health Organization. Tobacco Fact Sheet. 2018. Available online: https://www.who.int/news-room/ fact-sheets/detail/tobacco (accessed on 20 September 2019). 
24. Bremer, P.T.; Janda, K.D. Conjugate Vaccine Immunotherapy for Substance Use Disorder. Pharmacol. Rev. 2017, 69, 298-315. [CrossRef] [PubMed]

25. Zhao, Z.; Hu, Y.; Harmon, T.; Pentel, P.R.; Ehrich, M.; Zhang, C. Rationalization of a nanoparticle-based nicotine nanovaccine as an effective next-generation nicotine vaccine: A focus on hapten localization. Biomaterials 2017, 138, 46-56. [CrossRef]

26. Thorn, J.M.; Bhattacharya, K.; Crutcher, R.; Sperry, J.; Isele, C.; Kelly, B.; Yates, L.; Zobel, J.; Zhang, N.; Davis, H.L.; et al. The Effect of Physicochemical Modification on the Function of Antibodies Induced by Anti-Nicotine Vaccine in Mice. Vaccines 2017, 5, 11. [CrossRef] [PubMed]

27. Zhao, Z.; Hu, Y.; Harmon, T.; Pentel, P.R.; Ehrich, M.; Zhang, C. Hybrid nanoparticle-based nicotine nanovaccines: Boosting the immunological efficacy by conjugation of potent carrier proteins. Nanomedicine 2018, 14, 1655-1665. [CrossRef] [PubMed]

28. Fraleigh, N.L.; Boudreau, J.; Bhardwaj, N.; Eng, N.F.; Murad, Y.; Lafrenie, R.; Acevedo, R.; Oliva, R.; Diaz-Mitoma, F.; Le, H.T. Evaluating the immunogenicity of an intranasal vaccine against nicotine in mice using the Adjuvant Finlay Proteoliposome (AFPL1). Heliyon 2016, 2, e00147. [CrossRef] [PubMed]

29. Fraleigh, N.L.; Oliva, R.; Lewicky, J.D.; Martel, A.L.; Acevedo, R.; Dagmar, G.R.; Le, H.T. Assessing the immunogenicity and toxicity of the AFPL1-conjugate nicotine vaccine using heterologous and homologous vaccination routes. PLoS ONE 2019, 14, e0221708. [CrossRef] [PubMed]

30. Le, H.T.; Le Foll, B.; Le, D.A.; Murad, Y. Development of novel lung mucosal vaccine for smoking cessation treatment. CIHR Project Grant PJT-148531, 2016-2020. Available online: http://webapps.cihr-irsc.gc.ca/ decisions/p/project_details.html?applId=344049\&lang=en (accessed on 1 March 2016).

31. Pentel, P.R.; LeSage, M.G. New directions in nicotine design and use. Adv. Pharmacol. 2014, 69, 553-580.

32. McCluskie, M.J.; Thorn, J.; Gervais, D.P.; Stead, D.R.; Zhang, N.; Benoit, M.; Cartier, J.; Kim, I.J.; Bhattacharya, K.; Finneman, J.I.; et al. Anti-nicotine vaccines: Comparison of adjuvanted CRM197 and Qb-VLP conjugate formulations for immunogenicity and function in non-human primates. Int. Immunopharamacol. 2015, 29, 663-671. [CrossRef]

33. Zhao, Z.; Harris, B.; Hu, Y.; Harmon, T.; Pentel, P.R.; Ehrich, M.; Zhang, C. Rational incorporation of molecular adjuvants into a hybrid nanoparticle-based nicotine vaccine for immunotherapy against nicotine addiction. Biomaterials 2018, 155, 165-175. [CrossRef]

34. Zeigler, D.F.; Roque, R.; Clegg, C.H. Optimization of a multivalent peptide vaccine for nicotine addiction. Vaccine 2019, 37, 1584-1590. [CrossRef] [PubMed]

35. Chen, X.Z.; Zhang, R.Y.; Wang, X.F.; Yin, X.G.; Wang, J.; Wang, Y.C.; Liu, X.; Du, J.J.; Liu, Z.; Guo, J. Peptide-free Synthetic Nicotine Vaccine Candidates with $\alpha$-Galactosylceramide as Adjuvant. Mol. Pharm. 2019, 16, 1467-1476. [CrossRef] [PubMed]

36. Raymond, D.A.; Nilsson, B.L. Multicomponent peptide assemblies. Chem. Soc. Rev. 2018, 47, 3659-3720. [CrossRef] [PubMed]

37. Lewicky, J.D.; Martel, A.L.; Fraleigh, N.L.; Boraman, A.; Nguyen, T.M.D.; Schiller, P.W.; Shiao, T.C.; Roy, R.; Le, H.T. Strengthening peptide-based drug activity with novel glyconanoparticle. PLOS ONE 2018, 13, e0204472. [CrossRef]

38. Daw, K.; Baghdayan, A.S.; Awasthi, S.; Shankar, N. Biofilm and planktonic Enterococcus faecalis elicit different responses from host phagocytes in vitro. FEMS Immunol. Med. Microbiol. 2012, 65, 270-282. [CrossRef]

39. Martinon, F.; Burns, K.; Tschopp, J. The inflammasome: A molecular platform triggering activation of inflammatory caspases and processing of proIL-beta. Mol. Cell. 2002, 10, 417-426. [CrossRef]

40. Staats, H.F.; Ennis, E.A., Jr. IL-1 is an effective adjuvant for mucosal and systemic immune responses when coadministered with protein immunogens. J. Immunol. 1999, 162, 6141-6147.

41. Gwinn, W.M.; Kirwan, S.M.; Wang, S.H. Effective induction of protective systemic immunity with nasally-administered vaccines adjuvanted with IL-1. Vaccine 2010, 28, 6901-6914. [CrossRef]

42. Khoruts, A.; Osness, R.E.; Jenkins, M.K. IL-1 acts on antigen-presenting cells to enhance the in vivo proliferation of antigen-stimulated naïve CD4 T cells via a CD28-dependent mechansism that does not involve increased expression of CD28 ligands. Eur. J. Immunol. 2004, 34, 1085-1090. [CrossRef] 
43. Ben-Sasson, S.Z.; Hu-Li, J.; Quiel, J. IL-1 acts directly on CD4 T cells to enhance their antigen-drived expansion and differentiation. Proc. Natl. Acad. Sci. USA 2009, 106, 7119-7124. [CrossRef]

44. Dinarello, C.A. Immunological and inflammatory function of the interleukin-1 family. Annu. Rev. Immunol. 2009, 106, 519-550. [CrossRef] [PubMed]

Sample Availability: Samples are not available from the authors.

(C) 2020 by the authors. Licensee MDPI, Basel, Switzerland. This article is an open access article distributed under the terms and conditions of the Creative Commons Attribution (CC BY) license (http://creativecommons.org/licenses/by/4.0/). 